\title{
26. SKEWNESS OF MAGNETIC ANOMALIES M0 TO M29 IN THE NORTHWESTERN PACIFIC ${ }^{1}$
}

\author{
Roger L. Larson ${ }^{2}$ and William W. Sager ${ }^{3}$
}

\begin{abstract}
M-sequence magnetic anomalies from the Phoenix, Japanese, and Hawaiian lineation patterns in the western Pacific have been analyzed for cross-sectional skewness to determine a paleomagnetic apparent polar wander path for the Pacific plate for the Early Cretaceous and Late Jurassic. Results from magnetic anomalies M0 to M29 have been averaged to yield pole locations ranging in age from 122 to $155 \mathrm{Ma}$ both with and without the possibility of anomalous skewness. In either case these results show that the Pacific plate was moving south from 155 to $129 \mathrm{Ma}$ (Kimmeridgian to Hauterivian). The plate then reversed this motion and began to move slowly to the north. The M-sequence skewness data have been combined with younger poles from seamounts to show that this slow northward drift continued until about $82 \mathrm{Ma}$, when the Pacific plate began moving more rapidly to the north. This northward drift has continued at varying rates since that time.

A discrepancy in the skewness of the Phoenix lineations relative to the Hawaiian and Japanese lineations becomes apparent just prior to M10n time and grows to a maximum at M29 time. This could be due to a yet-undiscovered plate (called here the Stealth plate) that lay between the Pacific plate and the Phoenix lineations from M10n to M29 time. Alternatively, it could be due to time-varying anomalous skewness resulting, perhaps, from changes in magnetic field strength during normal or reversed polarity intervals, causing the magnetization pattern to differ from the assumed "square-wave" shape. Both interpretations imply similar types of north-south motion for the Pacific plate; however, the anomalous skewness interpretation also implies a large component of clockwise rotation from 145 to $82 \mathrm{Ma}$.
\end{abstract}

\section{INTRODUCTION}

We know less about the history of motion of the Pacific plate than most of the other major plates because it is almost entirely hidden beneath the Pacific Ocean. Oriented paleomagnetic samples can only be collected from some of its younger islands. Models for its motion (Lancelot and Larson, 1975; Lancelot, 1978) relative to a fixed hotspot reference frame can be calculated with some confidence back to $70 \mathrm{Ma}$, and with less certainty to $125 \mathrm{Ma}$, based on the trends and ages of the Hawaiian, Emperor, and Line Islands seamounts and other congruent seamount chains. However, extension of these models to earlier times is difficult because the Pacific plate was subjected to a huge mid-Cretaceous volcanic episode (Schlanger et al., 1981; Larson, 1991) that obliterated much of the trend and age data for older hotspot seamount chains.

Paleomagnetic pole locations can be calculated from the shapes of magnetic anomalies over seamounts and magnetic lineation patterns to augment the history of plate motion. These pole locations can be combined with the ages of these structures to construct a paleomagnetic apparent polar wander path (APWP) that in turn can be used to calculate the paleolatitude history of various locations on the plate. In this paper we analyze the cross-sectional shape, or skewness, of the M-sequence magnetic anomalies M0 to M29 on the Pacific plate (Fig. 1) which range in age from 118 to $160 \mathrm{Ma}$ (Kent and Gradstein, 1985 ) in order to calculate a series of paleomagnetic poles that make up an APWP for that period. These calculations are combined with an APWP based on magnetic anomalies over seamounts for 39 to $88 \mathrm{Ma}$ (Sager and Pringle, 1988). The combined result is an APWP for almost the entire history of the Pacific plate from 0 to $155 \mathrm{Ma}$ that is used to calculate the paleolatitude history of Ocean Drilling Program (ODP) Leg 129 Sites 800,801 , and 802 . This paleolatitude history can then be compared with hotspot motion models, with remanent magnetic

\footnotetext{
'Larson, R. L., Lancelot. Y., et al., 1992. Proc. ODP. Sci. Results, 129: College Station, TX (Ocean Drilling Program).

${ }^{2}$ Graduate School of Oceanography, University of Rhode Island, Narragansett, RI, 02882, U.S.A.

${ }^{3}$ Department of Oceanography, Texas A\&M University, College Station, TX 77843 ,
}

inclination and age data from the aforementioned and other sites on the Pacific plate, and with indications of paleoequatorial crossings from micropaleontological/paleoecological analyses.

When considering this APWP based mainly on magnetic anomalies and the Pacific plate motion predicted by the APWP, it must be remembered first that the poles are calculated by assuming simplified magnetization distributions. The seamounts are generally assumed to be uniformly magnetized, and the magnetization distributions across the strikes of magnetic lineation patterns are assumed to have shapes resembling square waves or "boxcars." The motion of the Pacific plate is then calculated assuming that the paleomagnetic field approximated an axial dipole and that there has been no true polar wander in the past $155 \mathrm{Ma}$. Non-dipole components (NDC) and true polar wander (TPW) may account for differences when comparing the results presented here with hotspot models or paleontological data.

\section{METHOD}

The concept that the systematic variation in cross-sectional shape, or skewness, of magnetic anomalies is determined by the corresponding systematic variation in the remanent magnetization directions of the source layer was developed by Gay (1963) and Schouten (1971). They quantified the skewness of magnetic anomalies generated by a two-dimensional structure with a square wave magnetization distribution made up of constant magnetization intensity and alternating polarity. This skewness is a function of various magnetization directions and the strike of the structure through the following relationships:

skewness parameter $=\Theta=\mathrm{T}+\mathrm{I}_{\mathrm{R}}^{\prime}-180^{\circ}$,

where, $\mathrm{I}=$ effective present-day magnetic inclination, $\mathrm{I}_{\mathrm{R}}=$ effective remanent magnetic inclination, and

$$
\begin{aligned}
& \tan \Gamma^{\prime}=\tan I / \sin (A-D) \\
& \tan I_{R}=\tan I_{R} / \sin \left(A-D_{R}\right),
\end{aligned}
$$

where $I, I_{R}=$ present-day and remanent magnetic inclination; $D, D_{R}$ $=$ present-day and remanent magnetic declination; and $\mathrm{A}=$ along- 


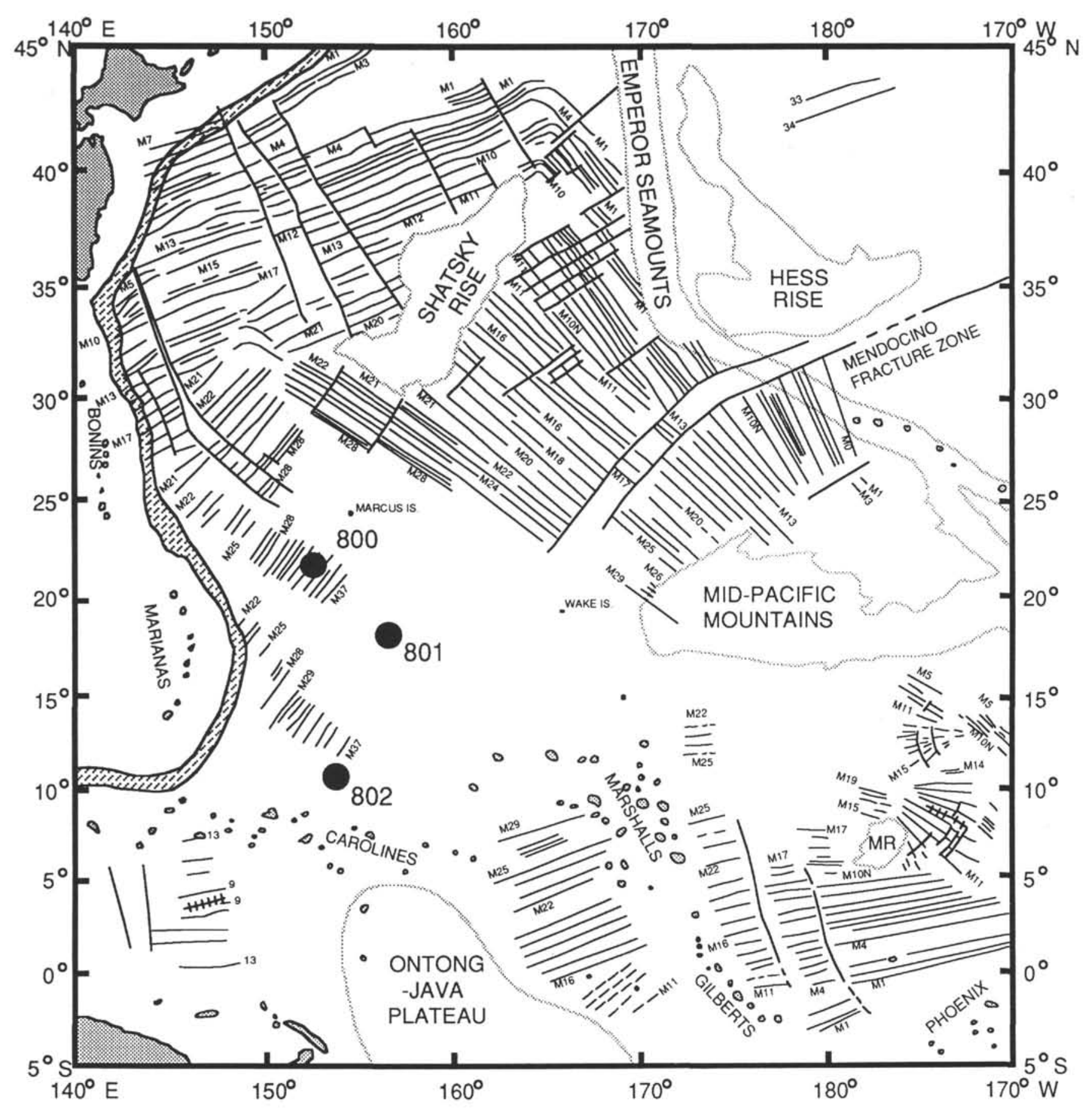

Figure 1. Magnetic lineations of the western Pacific compiled from Nakanishi et al. (1989), Mammerickx and Sharman (1988), Larson (1976), Tamaki and Larson (1988), Handschumacher et al. (1988), and Hilde et al. (1976). Large dots are ODP Leg 129 site locations. MR stands for Magellan Rise.

strike direction of the structure such that $\mathrm{A}=$ positive cross-strike direction $+90^{\circ}$.

$\mathrm{I}, \mathrm{D}, \mathrm{A}$, and $\Theta$ are known or can be determined, leaving two unknowns, $I_{R}$ and $D_{R}$, in the original equation for $\Theta$. Its solutions consist of a family of pairs of $I_{R}, D_{R}$ values, each pair corresponding to a possible paleomagnetic pole location. These possible paleomagnetic pole locations form a locus of points that trace half a great circle on a globe. In practice, the variation in skewness values due to noise and other natural processes in a magnetic lineation pattern results in the conclusion that the actual paleomagnetic pole location is confined between two extreme skewness values corresponding to two great semicircles that meet at their end points. The enclosed area resembles a new moon in shape, and is thus called a "lune of confidence."

Schouten and Cande (1976), based on the theoretical work of Schouten and McCamy (1972), developed a precise method for determining and averaging the results so that more tightly constrained lunes (shaped like "newer" moons) could be calculated. This inverse modeling technique represents the magnetic anomaly profile in the Fourier transform domain and is made up of several terms. The one critical to this analysis is called the "phase filter" and $=\mathrm{e}^{-i \Theta}$, where $\Theta$ is the skewness of the magnetic anomaly profile. If some value of $\Delta \Theta$ is added to $\Theta$ in the frequency domain, then when the magnetic 
anomaly profile is inverse transformed to the space domain it will have an altered, or phase-shifted, skewness from the original observation. The value added to $\Theta$ necessary to bring the inverse transformed shape to precise symmetry is an estimate of the skewness, $\Theta$, of the original profile. Because precise symmetry is the shape the magnetic anomaly would have if it were formed at the north or south poles, where all magnetization vectors are vertical, the process has been referred to as "transformation to the pole" by Blakely and Cox (1972).

In practice, a relatively long track segment (Fig. 2) is first projected to a cross-strike direction and the magnetic anomalies identified (Fig. 3). The positive $(+x)$ cross-strike direction determines the azimuth $(\mathrm{A})$ used in the skewness determination for that profile such that $\mathrm{A}=$ positive cross-strike direction $+90^{\circ}$ (Fig. 4). The positive cross-strike direction is not always towards younger or older anomalies; usually it is set so that the top of the projected profile diagram has a northerly component. The projected profile is then phase shifted by incremental amounts of $\Theta$ (increments of $10^{\circ}$ in this analysis), and replotted with varying increments of phase shift. The phase shift closest to exact symmetry for each anomaly is an estimate of $\Theta$ for that anomaly (Fig. 3). In order to obtain enough skewness estimates to be statistically meaningful, adjacent magnetic anomalies are grouped and averaged. For this analysis, we divided magnetic anomalies M0 to M29 into five groups in order to calculate five paleomagnetic pole locations. All skewness estimates for a particular magnetic anomaly group on a particular magnetic lineation pattern were averaged to determine a mean value estimate $(\overline{\mathrm{X}}$; see Table 1) and standard deviation. The $95 \%$ confidence interval $( \pm \Delta \Theta)$ can then be calculated from

$$
\pm \Delta \Theta_{95 \%}=\frac{t_{N}(s)}{\sqrt{N}}
$$

where $\mathrm{N}=$ number of samples, $\mathrm{s}=$ standard deviation, $\mathrm{t} \mathrm{N}=$ critical $\mathrm{t}$-statistic value for $\mathrm{N}$ samples, $\mathrm{tN}>\mathrm{t}_{\infty}=1.96$.

The values of $\bar{X} \pm \Delta \Theta$ are the bounding values of the $95 \%$ confidence lune for that group of magnetic anomalies. We will be correct $95 \%$ of the time in concluding that the true mean value of $\Theta$ lies within that confidence lune.

If two or more magnetic lineation patterns of the same age were formed on the same plate (the Pacific plate, in this case) and have not been moved relative to each other (although the entire plate can move), then their confidence lunes can be combined to tightly constrain the paleomagnetic pole location. These lunes should intersect, and the intersection of two or more confidence lunes should enclose the paleomagnetic pole location. To calculate the most likely location and the associated $95 \%$ confidence ellipse of each pole (Table 2), the method of Gordon and Cox (1980) was employed. This is a maximum likelihood technique that weights each datum by the inverse of its squared error. It also propagates these errors to determine the $95 \%$ confidence region of the mean pole. The most likely pole locations of monotonically-aging lune intersections can then be connected to form an APWP for 122 to $155 \mathrm{Ma}$, an extension of an APWP based on seamount magnetizations from 39 to $88 \mathrm{Ma}$. Finally, great circle angular distances can be calculated from each APWP point to each Leg 129 drill site (or any other point on the Pacific plate older than the APWP point) to determine a paleolatitude history for each drill site.

\section{DATA ANALYSIS}

Marine magnetic anomaly data from the northwestern Pacific plate area (Fig. 1) were acquired from the National Geophysical Data Center (Boulder, CO) and plotted to select profile segments for analysis. The selected profile segments are shown in Figure 2. In general, we searched for long continuous track segments that avoid fracture zones, seamount chains, and oceanic plateaus. Magnetic anomaly identifications were aided by large-scale charts for the Japanese and Hawaiian lineations kindly provided by M. Nakan- ishi from Nakanishi et al. (1989) and for the Phoenix lineations from Larson (1976). Average strikes were measured for the lineation patterns and the data were projected to cross-strike directions. Often, several cross-strike directions per profile were used, especially for the Hawaiian lineations that have a somewhat fan-shaped lineation pattern. Magnetic anomalies were identified in the projected data, and some profiles were eliminated because no clear identifications were apparent.

The profiles with identifiable magnetic anomalies were then phase-shifted through about $180^{\circ}$ by $10^{\circ}$ increments to search for symmetry in the individual magnetic anomalies. Identification of symmetry was aided by comparison of these phase-shifted data to model magnetic anomalies calculated for similar spreading rates and $\Theta=0^{\circ}$, or exact symmetry. This is an important step because magnetized blocks of different widths adjacent to the magnetic anomaly in question can cause that anomaly to appear slightly asymmetric, even at $\Theta=0^{\circ}$. Cande (1976) pointed out that this effect can be significant, producing up to $10^{\circ}$ errors in the symmetry determination. We use the same definition for symmetry used by Cande (1976), that magnetic anomaly shape most closely resembling a model magnetic anomaly profile calculated for $\Theta=0^{\circ}$.

Not all identifiable magnetic anomalies produce good skewness results. The method works best on magnetic anomalies produced by relatively wide blocks with no adjacent or internal short events. Symmetry determination is aided by observing the change in shape of the anomaly across several tens of degrees of phase shift. Anomalies from wide blocks with "square wave" shapes will change shape in an obvious way through symmetry in this process, while anomalies from narrow blocks and with short-event contamination that resemble "sine waves" will change very little, making symmetry determination imprecise. In addition, skewness of magnetic anomalies older than M21 is difficult to determine because of their reduced amplitudes (Cande et al., 1978) that have the effect of lowering the signal-to-noise ratio for skewness determination. We found that the determination of symmetry for magnetic anomalies older than M29 was not practical for this reason. Although the M30 to M37 magnetic anomaly identifications are often clear and correlatable, the closely spaced magnetic reversals and very low amplitudes of these anomalies preclude symmetry determination more precisely than about $\pm 30^{\circ}$.

In order to obtain a statistically significant number of symmetry determinations, magnetic anomalies M0 to M29 were grouped into five groups and averaged for each lineation pattern. These groups are somewhat arbitrary and are not likely to have any tectonic significance, with one exception discussed later. We attempted to develop groups with equivalent time spans, but had to modify that goal to accommodate small numbers of symmetry determinations in certain cases. The number of symmetry determinations ranged from 6 to 58 for the final groups (see Table 1). The final groups are magnetic anomalies M0 to M4 (118-126 Ma), M5 to M10n (126-131 Ma), M10n+ to M15+ (131-140 Ma), M16 to M21 (140-150 Ma), and M21+ to M29 (150-160 Ma). The "+" convention used here indicates the normally magnetized block just older than the reversely magnetized block that is numbered. (All M-sequence magnetic anomaly numbers correspond to reversely magnetized blocks except for M2 and M4.)

Figure 5 shows lunes calculated by Larson and Chase (1972) from part of the present data set and with a method different from that used here. Instead of phase-shifting magnetic anomalies to symmetry, they qualitatively compared the shapes of model magnetic anomaly profiles to the shapes of the observed data. They concluded from this forward-modeling study that "most" of the observed shapes corresponded to skewness values described by the lunes in Figure 5. In comparison with the present analysis utilizing the phase-shifting technique, Larson and Chase's method calculated approximately the same answer. The precision of that answer, however, is considerably less than can be achieved by phase shifting, due to our ability to detect small differences from symmetric shapes after the data have been 


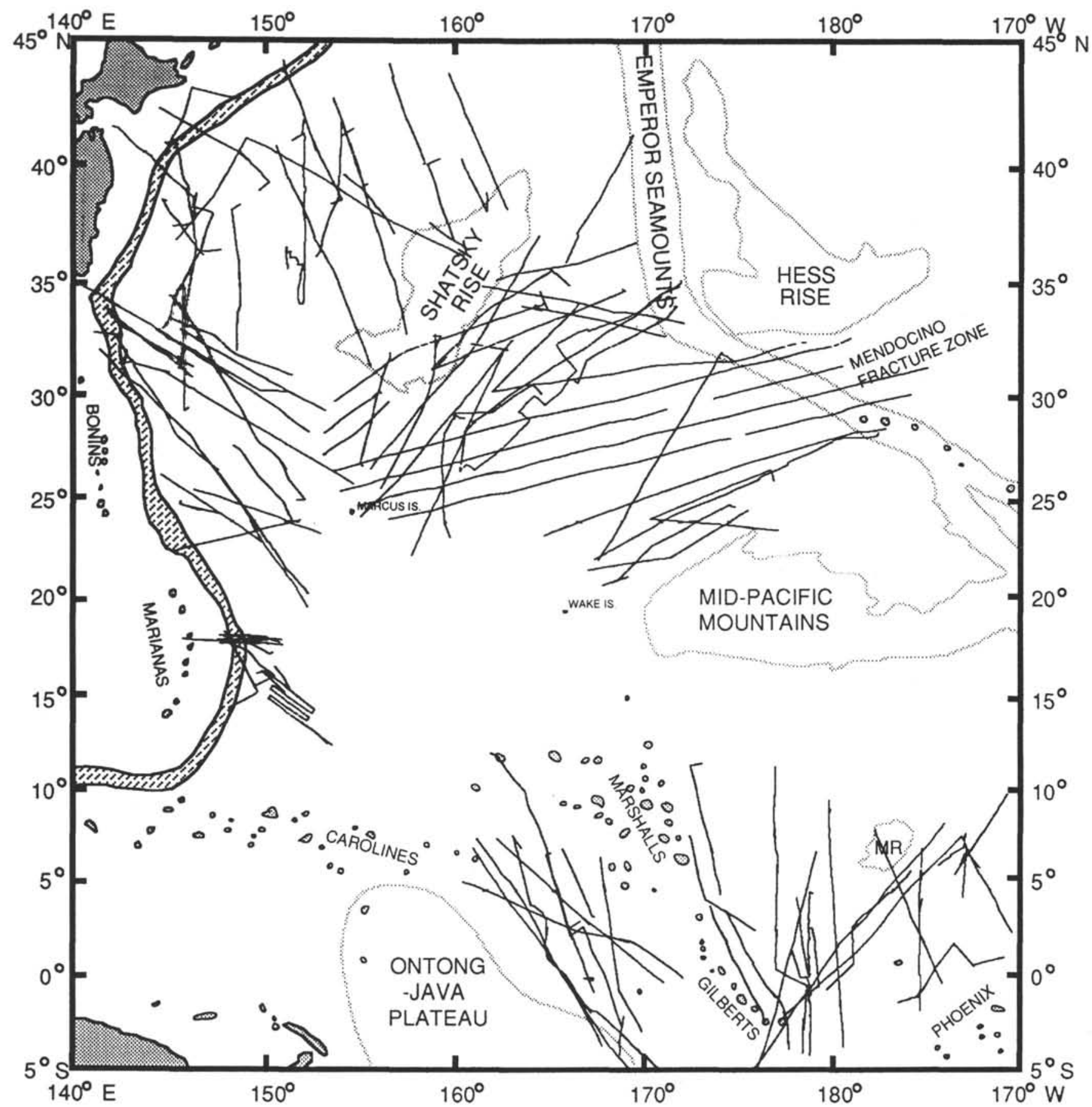

Figure 2. Track-line segments obtained from the National Geophysical Data Center (NGDC) and used in this skewness analysis.

transformed to the pole. These small differences are not nearly as obvious when the data are in their original, generally asymmetric, form. Also, the time resolution of that method is less than the phaseshifting technique, and the bounding lune values do not necessarily have the same statistical equivalency. Indeed Larson and Chase (1972) gave no precise definition to the limits between acceptable and unacceptable magnetic anomaly shapes. For all these reasons, we prefer the paleomagnetic pole locations calculated by the phase shifting technique.

Table 1 shows the results of the mean skewness determinations and the associated $95 \%$ confidence intervals. Generally speaking, the number of samples strongly affects the size of the confidence interval with smaller numbers of samples yielding larger confidence intervals. Aside from the numerical precision measured by the confidence intervals, we also have somewhat less confidence qualitatively in the $\mathrm{M} 21+$ to M29 anomaly groups than for the others. This results from the problems described above associated with skewness determinations on magnetic anomalies with relatively smaller amplitudes and more short events, both of which are inherent in the M21+ to M29 sequence. The problem of short events particularly makes exact skewness determination a more subjective process than it is otherwise. Thus, although the M21+ to M29 sequence might have a relatively small, and therefore precise, confidence interval, the possibility of some systematic bias in the skewness determinations exists 

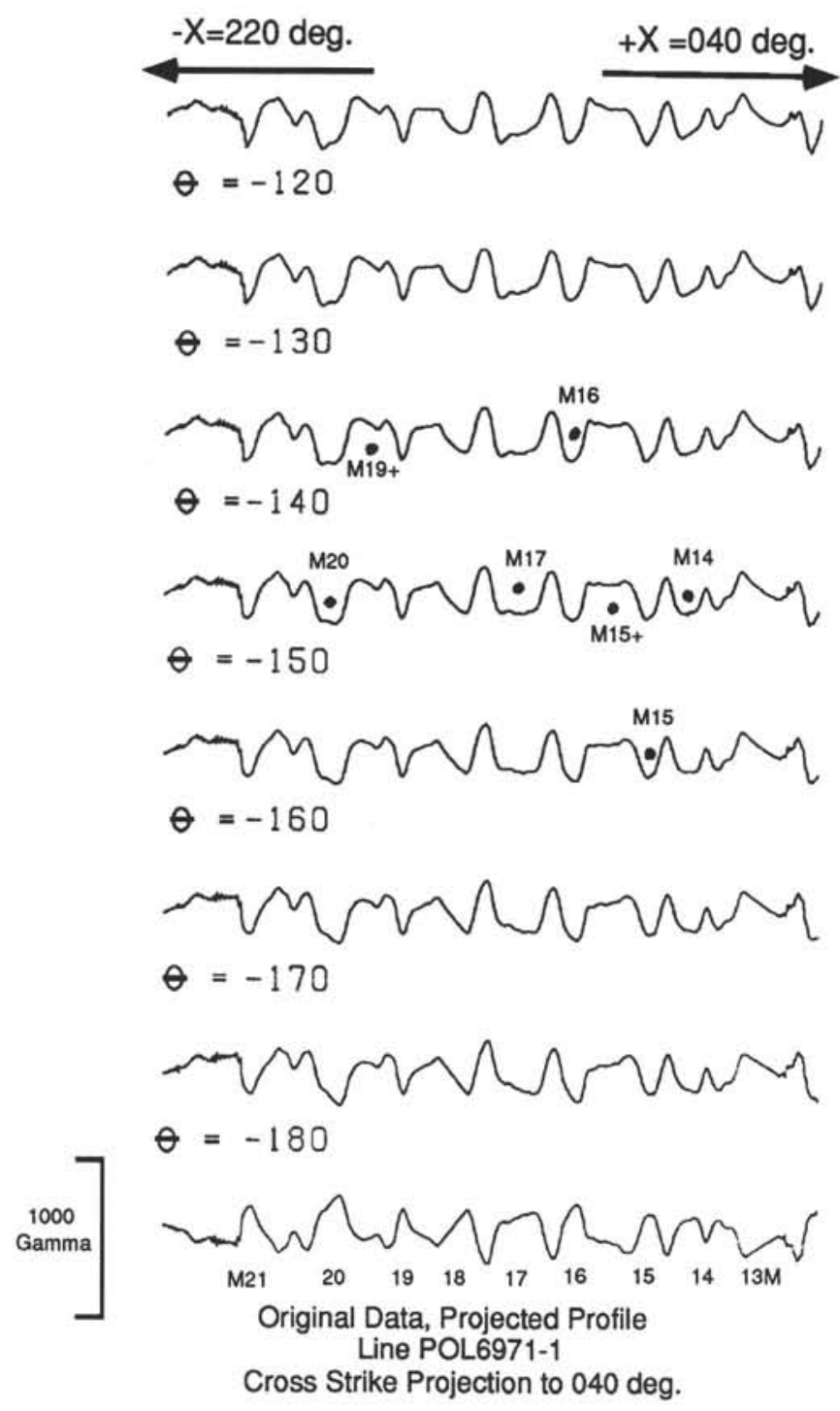

$150 \mathrm{Km}$

Figure 3. Sample magnetic anomaly profile projected to a cross-strike direction of $40^{\circ}$ across the Hawaiian lineation pattern and then phase shifted in increments of $\Theta=10^{\circ}$.

for these anomalies that is much less likely for the younger groups. A more detailed analysis, or preferably deep-towed data, may resolve this issue.

After skewness determination and averaging, the skewness values were converted to confidence lunes by merging them with ambient magnetic field directions and lineation azimuths. The azimuth determination is straightforward, and indeed is predetermined by the cross-strike projection directions, but the average ambient magnetization directions are sensitive to the average geographic center chosen for each lineation group, especially near the equator, where inclination values change rapidly. It is unlikely that significant errors have been introduced in this particular calculation because the lineation groups generally do not cover large areas.

\section{INTERPRETATION}

Lune intersections of lineation groups with the same age that have been accreted onto the same rigid plate are interpreted as enclosing
Map View

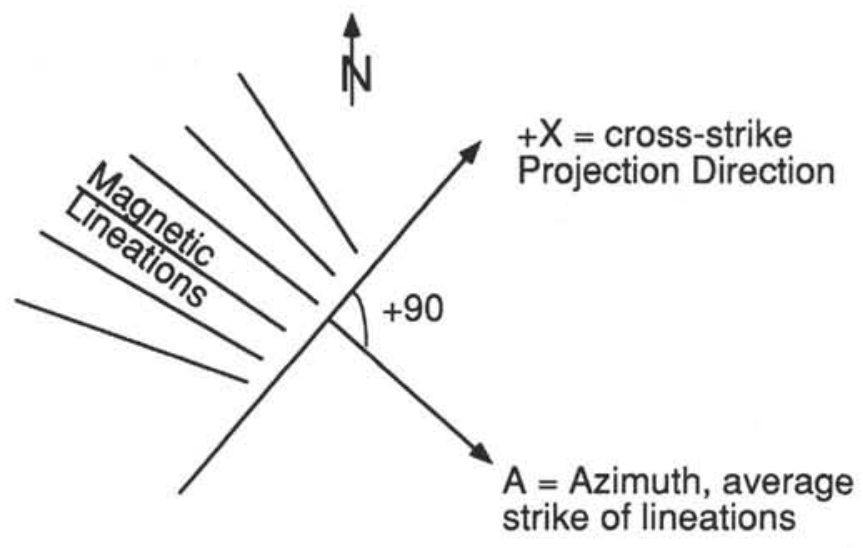

Figure 4. Diagram illustrating the relationship between magnetic lineation azimuth (A) and the positive $(+\mathrm{X})$ cross-strike projection direction such that $\mathrm{A}=$ positive cross-strike direction $+90^{\circ}$.

the paleomagnetic pole locations for the plate at the lineation age in question. If these lunes do not intersect, it is likely that one of the original assumptions is in error. Either the plate has not behaved rigidly, or the magnetization distributions across the strikes of the lineations are not sufficiently close to "square waves" or "boxcars." Intersections, or potential intersections, of skewness data are shown in Figures 6A-E. For clarity we have not shown the full lunes, but only great semicircles that correspond to the mean values of each of the skewness estimates. Examination of Figures $6 \mathrm{~A}$ and $6 \mathrm{~B}$ reveals that good intersections of the skewness data for all three lineation patterns are obtained for the magnetic anomalies M0 to M10n. This suggests that both of the above assumptions are probably correct to the precision of our observations. However, examination of Figures 6C-E reveals that a discrepancy in the skewness of the Phoenix lineations relative to the Hawaiian and Japanese lineations becomes apparent just prior to M10n time and grows to a maximum at M29 time. This could be due to a yet-undiscovered plate (called here the Stealth Plate) that lay between the Pacific plate and the Phoenix lineations from M10n to M29 time in a manner illustrated in Figure 7. Alternatively, it could be due to time-varying anomalous skewness that might be explained by changes in magnetic field strength during normal or reversed polarity intervals, giving rise to a non-"square wave" magnetization distribution for the older lineations. We will first explore the possibility of time-varying anomalous skewness.

Cande (1976) first recognized the phenomenon of anomalous skewness by an analysis of Late Cretaceous-aged anomalies on both arms of the "Great Magnetic Bight" in the northeastern Pacific, where it is very likely that the assumption of rigid plate behavior is correct. His tightly constrained lunes did not intersect unless some constant skewness value (called the "anomalous skewness") was added to the skewness values of both lunes. It was subsequently determined that a similar skewness anomaly exists for these anomalies on either side of the Pacific-Antarctic Ridge in the South Pacific. The size of this anomaly (sometimes up to $40^{\circ}$ ) precludes an explanation of block rotation at the ridge crest axis because such tilting has never been observed to exceed $10^{\circ}$. The potential space problem created by such strongly tilted blocks also argues against this possibility. Some portions of the marine magnetic record do not exhibit anomalous skewness, such as the M0 to M10n sequences analyzed here (Larson and Chase, 1972; Cande and Kent, 1985), so the concept of time-varying anomalous skewness was proposed by Cande (1978). He suggested that this would result from the Earth's magnetic dipole field intensity behaving in a non-"square wave" manner during times of 
Table 1. Input parameters for skewness calculations and average skewness values for various times on the Phoenix, Japanese, and Hawaiian lineations.

\begin{tabular}{|c|c|c|c|c|c|c|c|c|c|c|}
\hline & \multicolumn{2}{|c|}{ Present position } & \multirow{2}{*}{$\begin{array}{c}\text { Strike of } \\
\text { lineations (A) }\end{array}$} & \multicolumn{2}{|c|}{ Present magnetization } & \multirow{2}{*}{$\begin{array}{l}\text { Number of } \\
\text { samples }(N)\end{array}$} & \multirow{2}{*}{$\underset{(\bar{X})}{\operatorname{Mean} \theta}$} & \multirow{2}{*}{$\begin{array}{l}95 \% \mathrm{CI} \\
( \pm \Delta \theta)\end{array}$} & \multicolumn{2}{|c|}{$95 \% \theta$ range } \\
\hline & (Latitude ${ }^{\circ} \mathrm{N}$ ) & (Longitude ${ }^{\circ} \mathrm{E}$ ) & & Inclination $=(I)$ & Declination $=(D)$ & & & & $(\theta \min )$ & $(\theta \max )$ \\
\hline \multicolumn{11}{|l|}{ Phoenix } \\
\hline M0 to M4 & 1 & -178 & 260 & -2 & 10 & 17 & -128.2 & 5.5 & -122.7 & -133.7 \\
\hline M5 to M10n & 4 & -178 & 260 & 4 & 10 & 47 & -135.1 & 5.0 & -130.1 & -140.1 \\
\hline $\mathrm{M} 10 \mathrm{n}+$ to $\mathrm{M} 15$ & 1 & 177 & 260 & -3 & 10 & 6 & -133.3 & 8.2 & -125.1 & -141.5 \\
\hline M16 to M21 & 2 & 171 & 255 & -6 & 10 & 15 & -151.3 & 10.7 & -140.6 & -162.0 \\
\hline $\mathrm{M} 21+$ to $\mathrm{M} 29$ & 5 & 165 & 250 & -2 & 9 & 26 & -169.6 & 4.4 & -165.2 & -174.0 \\
\hline \multicolumn{11}{|l|}{ Hawaiian } \\
\hline M0 to M4 & 30 & 175 & 145 & 42 & 8 & 18 & -140.6 & 6.2 & -134.4 & -146.8 \\
\hline M5 to MiOn & 30 & 175 & 145 & 42 & 8 & 29 & -143.4 & 5.8 & -137.6 & -149.6 \\
\hline $\mathrm{M} 10 \mathrm{n}+$ to M15 & 29 & 170 & 135 & 40 & 6 & 37 & -149.4 & 4.2 & -145.2 & -155.4 \\
\hline M16 to M21 & 27 & 169 & 130 & 37 & 6 & 58 & -137.1 & 4.2 & -132.9 & -141.3 \\
\hline $\mathrm{M} 21+$ to $\mathrm{M} 29$ & 25 & 165 & 127 & 33 & 5 & 22 & -151.4 & 5.8 & -145.6 & -157.2 \\
\hline \multicolumn{11}{|l|}{ Japanese } \\
\hline M0 to M4 & 40 & 155 & 250 & 52 & -4 & 6 & -231.7 & 14.7 & -217.0 & -246.4 \\
\hline M5 to M10n & 39 & 155 & 250 & 50 & -4 & 48 & -226.9 & 4.8 & -222.1 & -321.7 \\
\hline M10n+ to M15 & 37 & 152 & 250 & 48 & -3 & 22 & -229.5 & 5.7 & -223.8 & -235.2 \\
\hline M16 to M21 & 33 & 147 & 250 & 42 & -4 & 24 & -232.5 & 4.3 & -228.2 & -236.6 \\
\hline $\mathrm{M} 21+$ to $\mathrm{M} 29$ & 23 & 148 & 220 & 30 & -1 & 38 & -213.6 & 9.1 & -204.5 & -222.7 \\
\hline
\end{tabular}

Notes: Strike of lineations is positive cross-strike direction plus $90^{\circ}$. Present magnetization inclination and declination have down and east positive. Number of samples is the number of magnetic anomaly measurements for which skewness was determined. $\theta$ min and $\theta$ max are the bounding values of the $95 \%$ confidence lunes such that $\bar{X} \pm \Delta \theta=\theta$ min and $\theta$ max.

Table 2. Maximum-likelihood paleomagnetic pole locations with associated $95 \%$ confidence ellipse parameters for the Pacific plate for 0-155 Ma.

\begin{tabular}{|c|c|c|c|c|c|c|}
\hline \multirow[b]{2}{*}{ Seamount age or lineations $(\mathrm{Ma})$} & \multicolumn{2}{|c|}{$\begin{array}{l}\text { Maximum-likelihood } \\
\text { pole location }\end{array}$} & \multicolumn{3}{|c|}{ 95\% Error Ellipse } & \multirow{2}{*}{$\begin{array}{c}\text { Anomalous } \\
\text { skewness } \\
\text { (degrees) }\end{array}$} \\
\hline & (Latitude ${ }^{\circ} \mathrm{N}$ ) & (Longitude ${ }^{\circ} \mathrm{E}$ ) & Major & Minor & Az. major & \\
\hline \multicolumn{7}{|l|}{ Seamounts } \\
\hline 39 & 77.6 & 7.6 & 3.5 & 2.4 & 91 & - \\
\hline 72 & 70.0 & 3.6 & 3.2 & 1.9 & 91 & - \\
\hline 82 & 58.4 & 359.0 & 2.9 & 2.7 & 91 & - \\
\hline 88 & 56.6 & 330.7 & 3.8 & 3.1 & 41 & - \\
\hline \multicolumn{7}{|l|}{ Magnetic lineations, without anomalous skewness } \\
\hline M0 to M4 & 50.9 & 324.9 & 2.37 & 2.6 & 64 & 0 \\
\hline M5 to M10n & 48.3 & 322.2 & 9.7 & 1.9 & 70 & 0 \\
\hline${ }^{\mathrm{a}} \mathrm{M} 10 \mathrm{n}+$ to M15+ & 53.0 & 334.0 & 11.1 & 1.0 & 78 & 0 \\
\hline${ }^{\mathrm{a}} \mathrm{M} 16$ to $\mathrm{M} 21$ & 60.4 & 321.5 & 10.8 & 1.7 & 74 & 0 \\
\hline${ }^{\mathrm{a}} \mathrm{M} 21+$ to M29 & 61.0 & 357.4 & 14.8 & 2.3 & 103 & 0 \\
\hline \multicolumn{7}{|l|}{ Magnetic lineations, with anomalous skewness } \\
\hline M0 to M4 & 45.2 & 310.1 & 20.8 & 2.7 & 54 & 4 \\
\hline M5 to MiOn & 46.0 & 315.6 & 9.4 & 1.8 & 67 & 3 \\
\hline $\mathrm{M} 10 \mathrm{n}+$ to M15+ & 44.9 & 300.8 & 9.9 & 1.8 & 57 & 9 \\
\hline $\mathrm{M} 16$ to $\mathrm{M} 21$ & 42.7 & 276.5 & 7.6 & 1.3 & 45 & 12 \\
\hline $\mathrm{M} 21+$ to $\mathrm{M} 29$ & 51.9 & 277.4 & 5.1 & 1.1 & 49 & 22 \\
\hline
\end{tabular}

Notes: Seamount pole data from Sager and Pringle (1988, Table 2). Magnetic lineation poles illustrated in Figures 6A-E. "Major"' is the major semi-axis length (degrees), "minor" is the minor semi-axis length (degrees), and "Az major" is the azimuth of major axis (degrees clockwise from north).

${ }^{a}$ Calculated from only the Hawaiian and Japanese lineations.

anomalous skewness. Instead, dipole field intensity would continue to change during otherwise constant polarity periods, producing sloped tops and bottoms on the supposedly square wave magnetization distribution. Other solutions invoked have called for sloping vertical block boundaries in the lower part of the magnetized layer due to a time lag in thermoremanent magnetization acquisition (TRM) at that level (Blakely, 1976; Cande and Kent, 1976) or to chemical remanent magnetization build-up (Raymond and LaBrecque, 1987) for several million years after TRM acquisition. However, the latter two solutions do not explain the long-term time dependency. Indeed, there is no magnetohydrodynamic explanation for intensity "ramps" during normal or reversed polarity intervals. There is simply no good reason to exclude the possibility of such time-varying field intensity.
Figures 6A-E illustrate intersections of skewness data with and without the possibilities of anomalous skewness. The solid lines are solutions with no anomalous skewness, and the dashed lines include the varying amounts of anomalous skewness listed in Table 2. The shaded ovals represent the $95 \%$ confidence ellipses and the square and circle in each diagram represent the most likely pole locations for the solutions with and without anomalous skewness, respectively.

Examination of Figures $6 \mathrm{~A}$ and $6 \mathrm{~B}$ reveals that the mean skewnesses of the three lineation patterns form a near intersection for anomalies M0 to M4 and M5 to M10n. Those intersections can be improved slightly with the addition of small amounts $\left(3^{\circ}\right.$ and $\left.4^{\circ}\right)$ of anomalous skewness. Examination of Figures $6 \mathrm{C}-\mathrm{E}$ reveals that the mean values for the skewness of the Phoenix lineations begin a 


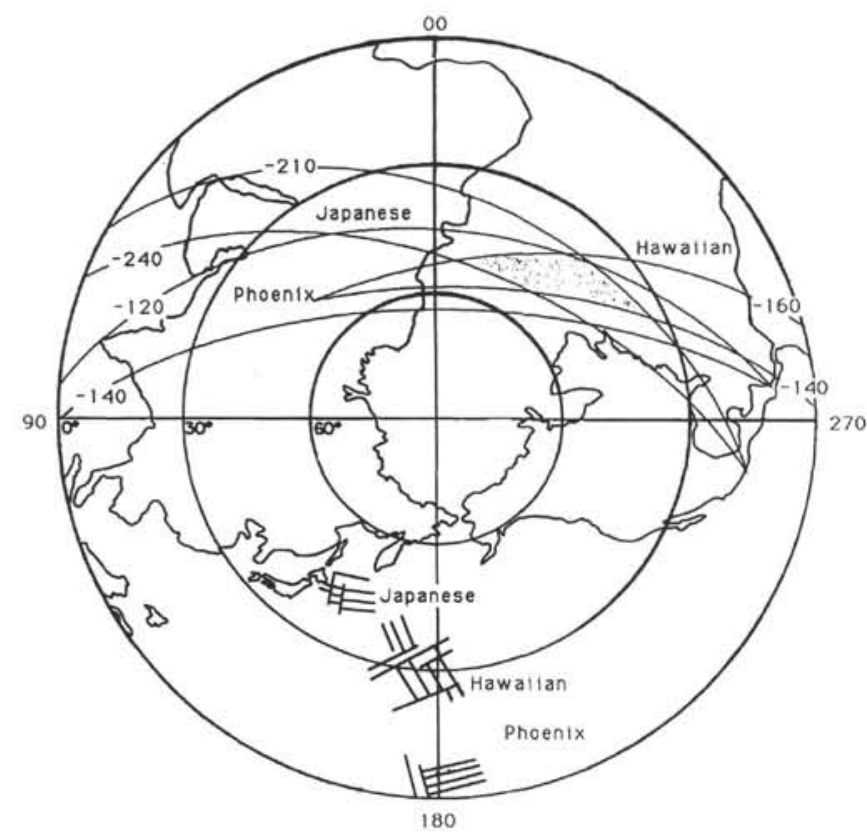

Figure 5. Phoenix, Hawaiian, and Japanese lunes calculated by a forward modeling method by Larson and Chase (1972) for magnetic anomalies M1 to M10.

systematic divergence from the intersections of the Japanese and Hawaiian lineations at M10n time that reaches a maximum at M29. Thus, the $95 \%$ confidence ovals for the intersections without anomalous skewness only apply to the Japanese-Hawaiian intersections for Figures $6 \mathrm{C}-\mathrm{E}$. These increasing divergences can be brought into intersections for each of the three time periods with increasing values of anomalous skewness $\left(9^{\circ}, 12^{\circ}\right.$, and $\left.22^{\circ}\right)$ as shown by the dashed great semicircles.

If we assume that the three lineation patterns have been rigidly connected to the Pacific plate since their formation, we can then interpret the above observations as a systematic increase in anomalous skewness going backwards in time from M10n to M29. As described above, this would most likely be due to an anomalous variation in dipole field intensity during otherwise constant-polarity intervals. Time variations of anomalous skewness of similar magnitudes have been observed in Cenozoic magnetic reversal sequences. One point in opposition to this interpretation is that the larger amounts of anomalous skewness required to fit the older anomalies push the intersections toward the nodes (the end points) of the Phoenix and Japanese semicircles in Figures $6 \mathrm{D}$ and $6 \mathrm{E}$. This is especially true for the Japanese lineations in Figure 6E. Amplitudes of anomalies should vary from a maximum in the centers of the great semicircles to zero at both ends, so this implies very low amplitudes for the older parts of the Japanese and Phoenix lineations. Such low amplitudes are not observed; however, it has always been difficult to quantify magnetic anomaly amplitudes, so this argument is not a strong one.

In contrast to the above interpretation, we could assume that no significant anomalous skewness characterizes the M0 to M29 magnetic anomaly patterns of the western Pacific. Then the systematic divergence of the Phoenix lineations skewness from that of the Hawaiian and Japanese lineations is explained by relative tectonic motion. As illustrated in Figure 7, this suggests that the Phoenix lineations older than M10n were not accreted originally onto the Pacific plate, and only became part of that rigid structure at M10n time. Instead, the simplest solution to the problem is to introduce an additional pair of spreading centers that would enclose another plate which we call the Stealth Plate to describe its covert nature. The Phoenix lineations thus would have formed on the Stealth Plate side of the Stealth/Phoenix plate boundary. Most of the poorly surveyed area south and west of the Mid-Pacific Mountains should contain the remains of Stealth/Pacific spreading that formed crust from M29 to M10n time. Possible evidence of the missing lineations is a series of anomalies, located at $12^{\circ} \mathrm{N}, 172^{\circ} \mathrm{E}$, that appear to be $\mathrm{M} 25$ to M22 aging in the direction opposite that of the Phoenix lineations. In the Stealth plate hypothesis, these lineations would have formed on the Stealth plate side of the Stealth/Pacific plate boundary. A problem with this observation is that these lineations appear on only one ship track, and that area has been alternatively interpreted as part of the normal Phoenix lineations by other investigators (Nakanishi et al., in press).

The Stealth plate hypothesis is a simple solution to the divergence of the Phoenix skewness data, but a space problem still exists. That is, the total space required by the skewness divergence on Figure $6 \mathrm{E}$ for Stealth/Pacific crust is about $18^{\circ}$ of latitude, while the total space available on Figure 1 is only $12^{\circ}$ (from $22^{\circ} \mathrm{N}$ to $10^{\circ} \mathrm{N}$ ). Forcing the divergence to its minimum value still requires $15^{\circ}$ of Stealth/Pacific spreading. This problem and the current lack of data and correlations in this area make it difficult to propose a more quantitative reconstruction. Subsequently, surveys in the broad, poorly surveyed zone south and west of the Mid-Pacific Mountains should be targeted toward unraveling the magnetic anomaly and tectonic fabric of this area to test this hypothesis.

Nakanishi et al. (in press) have proposed a third explanation for the skewness divergence of the Phoenix lineations in the Nauru Basin. They appeal to a combination of the original reversal pattern of Jurassic magnetization ( M10n to M29) overlain by subsequently emplaced mid-Cretaceous basalts that are entirely normally magnetized. They argue that a combination of different remanent magnetic inclinations for the Jurassic and Cretaceous basalts could produce the skewness discrepancy. While the subsequently emplaced Cretaceous basalts are certainly present in the Nauru Basin, we doubt that a uniformly magnetized layer of any constant magnetization will produce a change in the anomaly pattern, except at the boundaries of the layer. Furthermore, we point out that the skewness discrepancy occurs as a gradual build-up from M10n to M29 that would be more reasonably explained by time-varying anomalous skewness or by the evolution of the Stealth plate.

The most likely paleomagnetic pole locations for the Pacific plate from the preceding analysis can be combined with paleomagnetic pole locations for seamounts (Sager and Pringle, 1988) to construct a nearly-complete APWP for the Pacific plate from 0 to $155 \mathrm{Ma}$. The result is shown in Figure 8. Because the APWP has a complicated and overlapping pattern in the Mesozoic (prior to $72 \mathrm{Ma}$ ) the confidence ellipses from Figures 6A-E and the confidence ellipses of Sager and Pringle (1988) are not shown on Figure 8. Qualitatively, the confidence ellipses of the seamounts and the lineations are approximately equal. Prior to $88 \mathrm{Ma}$ the poles for the solutions both with and without anomalous skewness are shown on Figure 8. Both of these solutions show that the Pacific plate was not moving rapidly or continuously in a northerly or southerly direction prior to $88 \mathrm{Ma}$. The main difference in the two solutions is that the APWP without anomalous skewness suggests that the Pacific plate was not moving significantly in any sense relative to the paleomagnetic pole prior to $88 \mathrm{Ma}$. In contrast, the APWP that utilizes anomalous skewness indicates significant $\left(\sim 90^{\circ}\right)$ clockwise rotation of the Pacific plate from 145 to $82 \mathrm{Ma}$.

To construct the paleolatitude histories of the Leg 129 drill sites from these APWPs, we calculated the angular distance between each ODP drill site and each paleomagnetic pole location. Arcs drawn on the Earth's surface that subtend these angles are great circles connecting the drill sites to the pole locations, and represent paleolongitude lines connecting the sites to the north paleomagnetic pole at various times in the geological past. Thus, the subtended angles are the paleolatitudes of the drill sites as a function of geological time. 

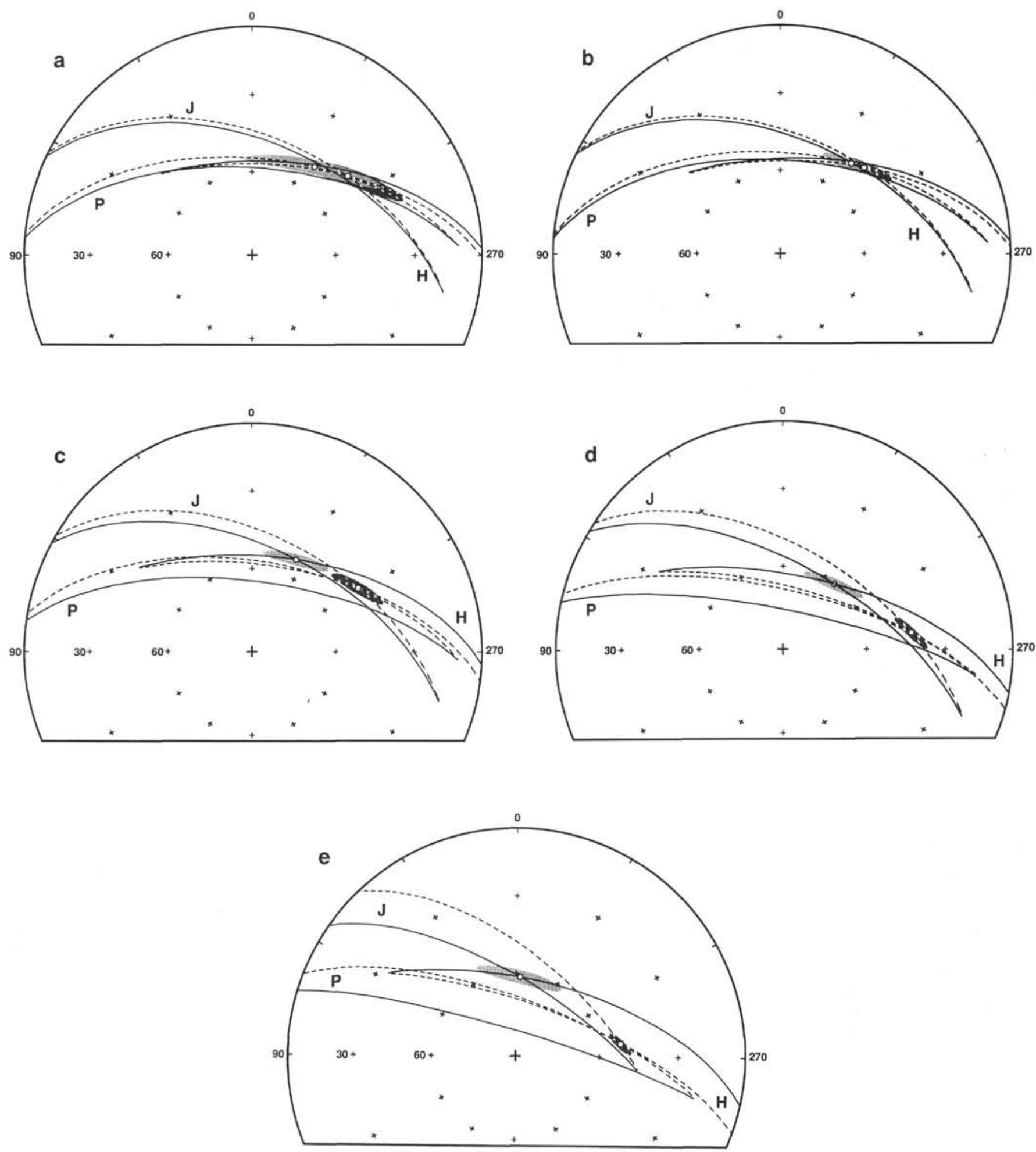

Figure 6. Phoenix, Hawaiian, and Japanese skewness intersection plots for the following periods: A. M0 to M4, 122 Ma; B. M5 to M10n, 129 Ma; C. M10n+ to M15+, $136 \mathrm{Ma}$; D. M16 to M21, $145 \mathrm{Ma}$; E. M21 to M29, $155 \mathrm{Ma}$. Only the mean value for each skewness determination is shown as a great semicircle, although the standard deviations from Table 1 were utilized to calculate the shaded $95 \%$ confidence ovals. The box and circle on each diagram represent the most likely intersections (pole locations) for the solutions with and without anomalous skewness, respectively. Solid great semicircles are skewness estimates without anomalous skewness and dashed great semicircles show skewness estimates with the anomalous skewness necessary to optimize the intersection for each time period. 


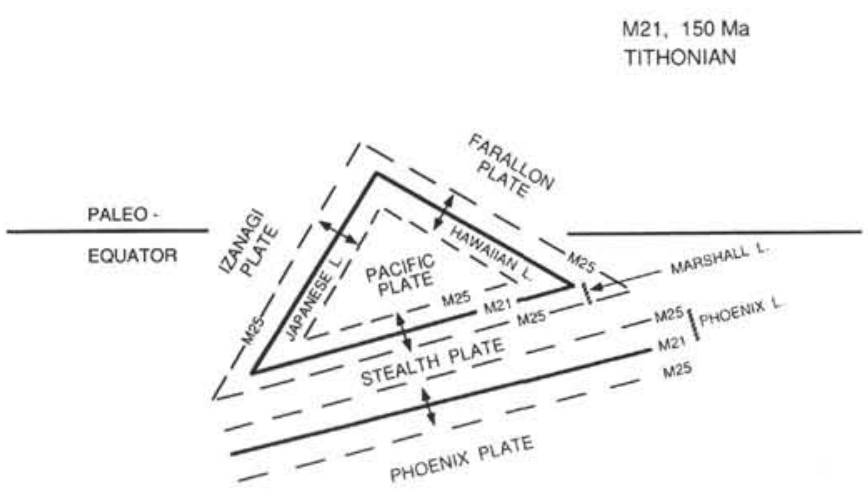

Figure 7. Tectonic sketch of the plates, plate boundaries, and ocean crust isochrons that could explain the divergence of the skewness of the Phoenix lineations from the skewness of the Hawaiian and Japanese lineations from M29 to M10n time. Oceanic crust created at the Stealth/Pacific plate boundary should now be located in the deep basin area south and west of the Mid-Pacific Mountains.

Figure 9 shows the predicted paleolatitude histories of the Leg 129 sites derived from the assumptions summarized in the "Introduction" (this chapter). It is interesting to note that the paleolatitude histories of the ODP drill sites prior to $88 \mathrm{Ma}$ are similar for both the solutions with and without anomalous skewness. The post-125 Ma part of this paleolatitude motion derived from the APWPs can be compared to motion models (Lancelot and Larson, 1975; Lancelot, 1978) based on fixed Pacific hotspots. This comparison shows small but significant discrepancies in the paleolatitude histories of these sites that might be due to true polar wander (TPW) since $70 \mathrm{Ma}$. That is, the Lancelot and Larson (1975) model would predict only $4^{\circ}$ of the northward motion between the present day and $40 \mathrm{Ma}$ for Site 801 , but $16^{\circ}$ of motion between 40 and $70 \mathrm{Ma}$. The APWP for the seamounts at 39 and $72 \mathrm{Ma}$ predict these values to be $10.5^{\circ}$ and $8^{\circ}$, respectively. These are offsetting discrepancies, and the total motion since 70 Ma predicted by both techniques is similar $\left(20^{\circ}\right.$ of northward motion since $70 \mathrm{Ma}$ by fixed Pacific hotspots vs. $18.5^{\circ}$ since $72 \mathrm{Ma}$ from the APWP). Both models also predict the equatorial crossing of Site 801 in the Paleocene-Maestrichtian (60 to $75 \mathrm{Ma}$ ). Site 800 is also predicted to cross the paleoequator at the same time by both methods (in the Maestrichtian, 65-75 Ma). However, Site 802 is predicted to cross the paleoequator in the Early Eocene (50-60 Ma) with the fixed hotspot model and in the early Oligocene-late Eocene (30-45 Ma) with the APWP.

The fixed-Pacific hotspot and APWP models also diverge at $>100 \mathrm{Ma}$ with the fixed-hotspot model predicting much higher southern paleolatitudes, probably due to poor control on the fixedhotspot model for the pre-Cenomanian. In general, we prefer the fixed-hotspot model for 0-70 Ma and the APWP models for 100-155 Ma. Both models predict essentially the same paleolatitude history for 70-100 Ma.

It is clear from these plots that the skewness analysis confirms the long-held notion (Uyeda and Richards, 1966; Francheteau et al., 1970) that the Pacific plate originated mainly in the Southern Hemisphere in the Mesozoic and has moved monotonically northwards since at least mid-Cretaceous ( $100 \mathrm{Ma})$ time. This analysis also confirms the speculation of Larson and Lowrie (1975) that sometime between M21 time (150 Ma) and M9 time (129 Ma) the Pacific plate was moving south. There is some possibility that the oldest part (Bathonian) of the Pacific plate at Site 801 was formed north of the equator and has experienced two equatorial passages. However, this earliest potential equatorial crossing cannot be confirmed by this analysis due to our inability to make skewness determinations on magnetic anomalies older than M29. If Site 801 crossed the equator

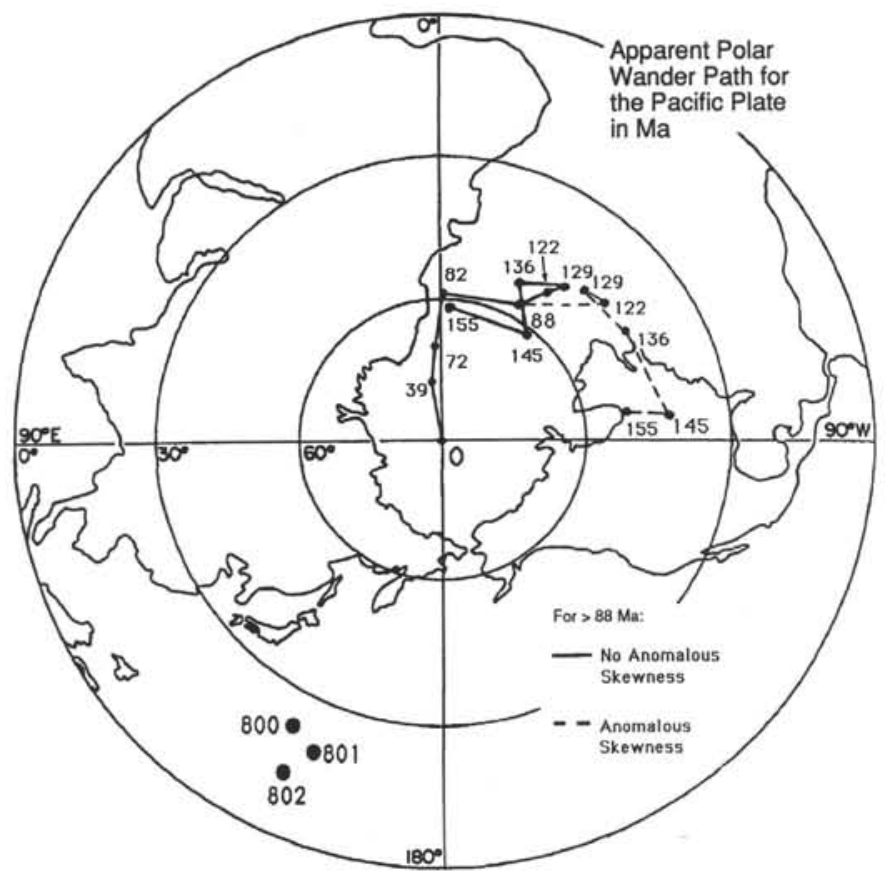

Figure 8. APWP based on seamounts from 39 to $88 \mathrm{Ma}$ and on magnetic lineations from 122 to $155 \mathrm{Ma}$. Seamount poles are from Sager and Pringle (1988) and magnetic lineations poles are from Figure 6 and Table 2 of this chapter.

from north to south in the Jurassic, this would have to have occurred prior to the Kimmeridgian ( $155 \mathrm{Ma}$ ).

Figure 9 indicates that the "turn around" in Pacific plate motion from southward to northward most likely occurred between M5 and M10n time (126 to $131 \mathrm{Ma}$ ), although extreme maximum and minimum paleolatitude estimates could be connected in ways to force the solution to somewhat older or younger ages. We note that this time coincides with the time of the cessation of spreading of the Magellan lineations (Tamaki and Larson, 1988) and with a world-wide reorganization of plate motion associated with the Early Cretaceous Gondwanaland fragmentation at about M10n time (Larson, 1976). The reversal in Pacific plate velocity from southward to northward motion at this time is additional evidence for the significance of this worldwide reorganization of plate motion.

\section{SUMMARY}

1. Magnetic anomalies of the M-sequence from the Phoenix, Japanese, and Hawaiian lineation patterns in the western Pacific have been analyzed for cross-sectional skewness to determine apparent paleomagnetic polar wander paths for the Pacific plate for the Early Cretaceous and Late Jurassic.

2. Magnetic anomalies M0 to M29 have been grouped to yield two different pole positions for solutions both with and without anomalous skewness for each of the following five intervals: M0 to M4, M5 to M10n, M10n+ to M15+, M16 to M21, and M21+ to M29.

3 . The three lineation patterns yield $95 \%$ confidence ellipses for the M0 to M4 and M5 to M10n groups that all intersect in two small areas, confirming the assumption of plate rigidity since M10n time and the more general calculations of Larson and Chase (1972) for this time interval.

4. Prior to M10n time the skewness of the Phoenix lineations diverges in a systematic way from the Hawaiian-Japanese skewness intersection, suggesting that the Phoenix lineations older than M10n were not accreted to the Pacific plate, or that the solutions involve significant anomalous skewness increasing from M10n to M29 time. 

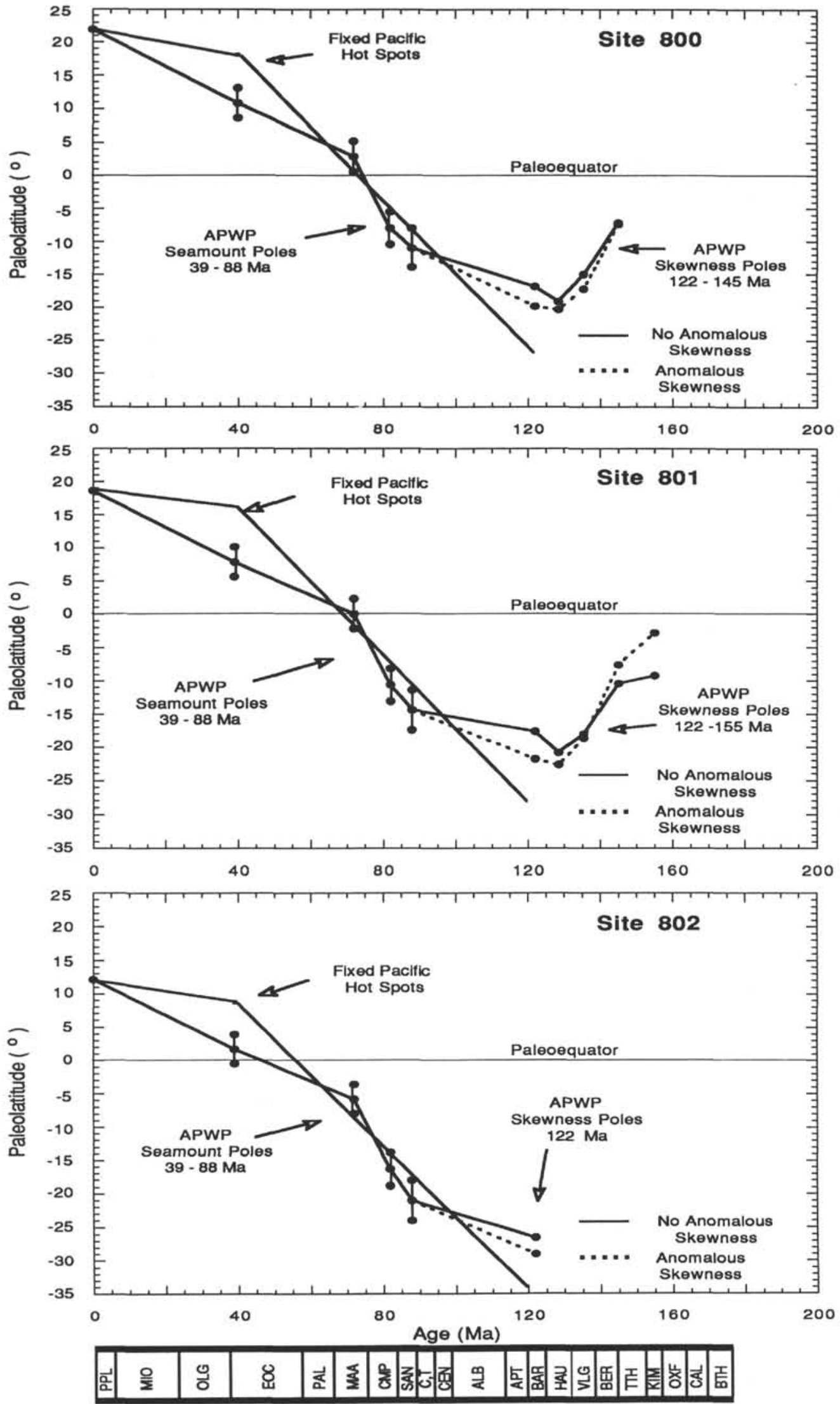

Figure 9. Predicted paleolatitudes for ODP Leg 129 drill site locations calculated from the APWP in Figure 8 for 0-155 Ma and from the fixed hotspot model of Lancelot and Larson (1975) and Lancelot (1978) for 0-125 Ma. Error bars from the seamount poles correspond to the limits of the $95 \%$ confidence ellipses. Similar-sized errors are associated with the magnetic lineation poles, but are not shown for clarity. 
Another yet undiscovered plate may have separated the Phoenix lineations from the Pacific plate to the north if the solution without anomalous skewness is correct. The evidence presently available does not strongly favor one model over the other.

5. The skewness intersections that locate the Pacific plate poles suggest that the Pacific plate was moving south from 155 to $128 \mathrm{Ma}$ (Kimmeridgian to Hauterivian time). The plate then reversed this motion and began moving slowly to the north. This applies to both the solutions with and without anomalous skewness.

6. The M-sequence skewness data have been combined with younger poles from seamounts to show that this slow northward drift continued until $82 \mathrm{Ma}$ when the Pacific plate began moving more rapidly to the north. The Pacific plate has been and continues to move monotonically to the north at varying rates since $82 \mathrm{Ma}$.

7. The Cenozoic-Late Cretaceous APWP results generally confirm the "Hawaiian" and "Emperor" rotations in the absolute motion model of Lancelot and Larson (1975) and Lancelot (1978). However, the "Line-Islands" rotation from that model moves the Pacific plate much farther south than would be predicted by the mid- to Early Cretaceous APWP results.

\section{ACKNOWLEDGMENT}

The senior author thanks Jim Dolan for his extraordinary efforts to convert computer programs and process these data in the midst of much other seagoing chaos and the author's sabbatical in France.

\section{REFERENCES}

Acton, G. D., and Gordon, R. G., 1991. A 65 Ma paleomagnetic pole for the Pacific plate from the skewness of magnetic anomalies 27r-31. Geophys. J. Int., 106:407-420.

Blakely, R. J., 1976. An age dependent, two layer model for marine magnetic anomalies. In Sutton, G. H., Manghanni, M. H., and Moberly, R. (Eds.), The Geophysics of the Pacific Ocean Basin and Its Margin. Am. Geophys. Union, Geophys. Monogr. Ser., 19:227-234.

Blakely, R. J., and, Cox, A., 1972. Identification of short polarity events by transforming marine magnetic profiles to the pole. J. Geophys. Res., 77:4339-4349.

Cande, S. C., 1976. A paleomagnetic pole from Late Cretaceous marine magnetic anomalies in the Pacific. Geophys. J. R. Astron. Soc., 44:547-566.

- 1978. Anomalous behavior of the paleomagnetic field inferred from the skewness of anomalies 33 and 34. Earth Planet. Sci. Lett., 40:275-286.

Cande, S. C., and Kent, D. V., 1976. Constraints imposed by the shape of marine magnetic anomalies on the magnetic source. J. Geophys. Res., $81: 4157-4162$.

-1985. Comment on "Tectonic rotations in extensional regimes and their paleomagnetic consequences for ocean basalts by K. L. Verosub and E. M. Moores." J. Geophys. Res., 90:4647-4651.

Cande, S. C., Larson, R. L., and LaBrecque, J. L., 1978. Magnetic lineations in the Pacific Jurassic Quiet Zone. Earth Planet Sci. Lett., 41:434-440.

Francheteau, J., Harrison, C.G.A., Sclater, J. G., and Richards, M. L., 1970. Magnetization of Pacific seamounts: a preliminary polar curve for the northeastern Pacific. J. Geophys. Res., 75:2035-2061.

Gay, S. P., 1963. Standard curves for interpretation of magnetic anomalies over long tabular bodies. Geophysics, 28:161-200.

Gordon, R. G., and Cox, A. V., 1980. Calculating paleomagnetic poles for oceanic plates. Geophys. J. R. Astron. Soc., 63:619-640.
Handschumacher, D. W., Sager, W. W., Hilde, T.W.C., and Bracey, D. R., 1988. Pre-Cretaceous tectonic evolution of the Pacific plate and extension of the geomagnetic polarity reversal time scale with implications for the origin of the Jurassic "Quiet Zones." Tectonophysics, 155:365-380.

Hilde, T.W.C., Isezaki, N., and Wageman, J. M., 1976. Mesozoic sea-floor spreading in the North Pacific. In Sutton, G. H., Manghnani, M. H., and Moberly, R. (Eds.), The Geophysics of the Pacific Ocean Basin and lts Margin. Am. Geophys. Union, Geophys. Monogr. Ser., 19:205-226.

Kent, D. V., and Gradstein, F. M., 1985. A Cretaceous and Jurassic geochronology. Geol. Soc. Am. Bull., 96:1419-1427.

Lancelot, Y., 1978. Relations entre evolution sedimentaire et tectonique de la plaque Pacifique dupuis le Cretace Inferieur. Mem. Soc. Geol. Fr., 134:1-40.

Lancelot, Y. L., and Larson, R. L., 1975. Sedimentary and tectonic evolution of the northwestern Pacific. Init. Repts. DSDP, 32: Washington (U.S. Govt. Printing Office), 925-939.

Larson, R. L., 1976. Late Jurassic and Early Cretaceous evolution of the western Central Pacific Ocean. J. Geomagn. Geoelectr., 28:219-236.

1991. Latest pulse of the Earth: evidence for a mid-Cretaceous super plume. Geology, 19:547-550.

Larson, R. L., and Chase, C. G., 1972. Late Mesozoic evolution of the western Pacific Ocean. Geol. Soc. Am. Bull., 83:3627-3644.

Larson, R. L., and Lowrie, W., 1975. Paleomagnetic evidence for motion of the Pacific plate from Leg 32 basalts and magnetic anomalies. In Larson, R. L., Moberly, R., et al., Init. Repts. DSDP, 32: Washington (U. S. Govt. Printing Office), 571-577.

Larson, R. L., and Schlanger., S. O., 1981. Cretaceous volcanism and Jurassic magnetic anomalies in the Nauru Basin, western Pacific Ocean. Geology, 9:480-484.

Mammerickx, J., and Sharman, G. F., 1988. Tectonic evolution of the North Pacific during the Cretaceous quiet period. J. Geophys. Res., 93:3009-3024.

Nakanishi, M., Tamaki, K., and Kobayashi, K., 1989. Mesozoic magnetic anomaly lineations and seafloor spreading history of the northwestern Pacific. J. Geophys. Res., 94:15437-15462.

Nakanishi, M., Tamaki, K., and Kobayashi, K., in press. Magnetic anomaly lineations from Late Jurassic to Early Cretaceous in the west-central Pacific Ocean. Geophys. J. Int.

Raymond, C. A., and LaBrecque, J. L., 1987. Magnetization of the oceanic crust: Thermoremanent magnetization or chemical remanent magnetization? J. Geophys. Res., 92:8077-8088.

Sager, W. W., and Pringle, M. S., 1988. Mid-Cretaceous to Early Tertiary apparent polar wander path of the Pacific plate. J. Geophys. Res., 93:11753-11771.

Schlanger, S. O., Jenkyns, H. C., and Premoli-Silva, I., 1981. Volcanism and vertical tectonics in the Pacific basin related to global Cretaceous transgressions. Earth Planet. Sci. Lett., 52:435-449.

Schouten, H., 1971. A fundamental analysis of magnetic anomalies over oceanic ridges. Mar. Geophys. Res., 1:111-114.

Schouten, H., and Cande, S. C., 1976. Palaeomagnetic poles from marine magnetic anomalies. Geophys. J. R. Astron. Soc., 44:567-575.

Schouten, H., and McCamy, K., 1972. Filtering marine magnetic anomalies. J. Geophys. Res., 77:7089-7099.

Tamaki, K., and Larson, R. L., 1988. Mesozoic tectonic history of the Magellan microplate in the western central Pacific. J. Geophys. Res., 93:2857-2874.

Uyeda, S., and Richards, M. L., 1966. Magnetization of four Pacific seamounts near the Japanese Islands. Tokyo Daigaku Jishin Kenkyusho Iho, 44:179-213.

Date of initial receipt: 15 May 1991

Date of acceptance: 10 February 1992

Ms 129B-137 